\title{
HUBUNGAN ANTARA SIKAP WANITA USIA SUBUR (WUS) DENGAN UPAYA DETEKSI DINI INSPEKSI VISUAL DENGAN ASAM ASETAT (IVA) DI DESA DAJAN PEKEN KABUPATEN TABANAN
}

\author{
Putu Adi Cahya Dewi ${ }^{1,2}$, Canriani Rante ${ }^{1,2}$, I Dewa Gede Murdita ${ }^{1,2}$ \\ ${ }^{1}$ Program Studi S1 Keperawatan Ners, ${ }^{2}$ STIKES Advaita Medika Tabanan \\ Korespodensi penulis: cahya.dewi1213@gmail.com
}

\begin{abstract}
Abstrak
Latar belakang: Deteksi dini kanker serviks dengan Asam Asetat (IVA) merupakan terobosan inovatif dalam pembangunan kesehatan untuk mengurangi angka kematian dan kesakitan akibat kanker serviks. Pemahaman para kaum wanita tentang deteksi dini terhadap kanker serviks, perlu ditingkatkan untuk mendorong, dan memotivasi dalam mengambil sikap yang lebih baik.

Tujuan: Mengetahui hubungan antara antara Sikap Wanita Usia Subur (WUS) dengan Upaya Deteksi Dini Inspeksi Visual dengan Asam Asetat (IVA) di Desa Dajan Peken Kabupaten Tabanan.

Metode: Penelitian ini adalah penelitian kuantitatif dengan dengan rancangan analitik korelatif, dengan pendekatan cross sectional. Dalam penelitian ini menggunakan non probability sampling dengan teknik Purposive sampling dengan jumlah sampel sebanyak 71 responden. Uji analisis yang digunakan yaitu $C h-i$ Square dengan nilai signifikansi 0,05 .

Hasil: Berdasarkan hasil penelitian diperoleh sikap wanita usia subur sebagian besar cukup yaitu sebanyak 44 responden $(62,0 \%)$ dan upaya wanita usia subur dalam deteksi dini kanker serviks dengan IVA adalah sebagian besar yang sudah pernah IVA sebanyak 56 responden $(78,9 \%)$. Hasil uji korelasi dengan menggunakan Chi-Square yaitu didapatkan hasil $p$ value $0,000<\alpha 0,05$ dan hasil hitung $\mathrm{x}^{2}$ diperoleh nilai $\mathrm{x}^{2}$ hitung 15,845 $>\mathrm{x}^{2}$ tabel 5,991yang berarti ada hubungan antara antara Sikap Wanita Usia Subur (WUS) dengan Upaya Deteksi dini Inspeksi Visual dengan Asam Asetat (IVA).

Simpulan: Ada hubungan antara antara Sikap Wanita Usia Subur (WUS) dengan Upaya Deteksi Dini Inspeksi Visual dengan Asam Asetat (IVA) di Desa Dajan Peken Kabupaten Tabanan.
\end{abstract}

Kata kunci: IVA, Kanker Serviks, Sikap, WUS

\section{Pendahuluan}

Banyak sekali permasalahan yang menyangkut kesehatan reproduksi ini, salah satunya adalah kanker serviks yang merupakan pembunuh wanita pertama di dunia (Bertiani, S. 2017). Kanker serviks atau yang lebih dikenal dengan istilah kanker leher rahim adalah tumbuhnya sel-sel tidak normal pada leher rahim. Kanker ini biasanya terjadi pada wanita yang berusia antara 30 tahun sampai dengan 50 tahun, yaitu pada puncak usia reproduktif wanita sehingga akan menyebabkan gangguan kualitas hidup secar fisik, kejiwaan dan kesehatan seksual (Smart, 2015).

Berdasarkan laporan Internasional Agency for Research on Cancer (IARC) pada tahun 2012 didapatkan data sebanyak 14,0\% kejadian baru dengan kanker serviks pada penduduk dunia. Data menunjukkan sebanyak 6,8\% kasus kanker serviks pada penduduk dunia berakhir dengan kematian (Kementrian Kesehatan RI Pusat Data dan Informasi Kesehatan, 2015). Di Indonesia berdasarkan Riset Kesehatan Dasar pada tahun 2018 prevalensi penyakit kanker di Indonesia mengalami peningkatan dari $1,4 \%$ 
(Riskesdas 2013) menjadi 1,8\% (Kementerian RI, 2018). Berdasarkan hasil Riset Kesehatan Dasar pada tahun 2013 didapat hasil sebanyak 98.692 kasus dengan kanker serviks pada penduduk Indonesia.

Berdasarkan laporan Dinas Kesehatan Provinsi Bali tahun 2016 mencatat di Provinsi Bali sebanyak 775 kasus kanker serviks yang dengan rawat jalan, sebanyak 334 kasus kanker serviks dengan rawat inap, dan sebanyak 13 kasus kanker serviks yang meninggal. Berdasarkan data dari Dinas Kesehatan Kabupaten Tabanan jumlah kasus kanker serviks setiap tahun semakin meningkat. Hal ini dilihat dari jumlah kasus kanker serviks tahun 2017 sebanyak 15 orang, 2018 sebanyak 47 orang dan tahun 2019 sebanyak 77 orang.

Dalam mengatasi lonjakan angka kejadian kanker serviks, perlu adanya skrining untuk mengetahui stadium kanker serviks, salah satu faktor utama adalah penemuan stadium lebih awal dengan deteksi dini. Deteksi dini kanker serviks merupakan terobosan inovatif dalam pembangunan kesehatan untuk mengurangi angka kematian dan kesakitan akibat kanker serviks. IVA adalah sebuah metode deteksi dini kanker serviks dengan cara inspeksi visual pada serviks dengan aplikasi asam asetat. Metode inspeksi visual lebih mudah, lebih mampu dilaksanakan, sehingga deteksi dini dapat dilakukan dengan cakupan lebih luas. Namun semakin banyak pemahaman para kaum wanita tentang deteksi dini terhadap kanker serviks, maka para kaum wanita akan semakin terdorong, termotivasi untuk mengambil sikap yang lebih baik. (Septiani, 2017).

Faktor keengganan menjadi salah satu masalah bagi perempuan untuk bersedia melakukan deteksi dini kanker serviks, keengganan tersebut terjadi dikarenakan merasa malu saat dilakukan pemeriksaan. Penyebab lainnya adalah keraguan akan pentingnya pemeriksaan deteksi dini, kurangnya pengetahuan tentang pentingnya pemeriksaan, dan takut akan kenyataan hasil pemeriksaan. Faktor penyebab yang lain dari kanker serviks adalah hubungan seks terlalu dini, terlambat menikah, dan berganti-ganti pasangan (Martini, 2016).

Berdasarkan penelitian $\mathrm{Ni}$ Made, dkk (2016) masalah yang berkaitan dengan wanita yang enggan melakukan deteksi dini kanker serviks ini dapat dihilangkan melalui pengetahuan tentang skrining kanker serviks, karena jika pengetahuan wanita usia subur membaik akan merubah sikap negatif menjadi sikap positif. Hasil penelitian Lindayati Yati (2017) responden memiliki sikap positif dan $52,7 \%$ responden melakukan tindakan pencegahan penyakit kanker serviks dengan baik.

Berdasarkan hasil studi pendahuluan pada bulan Agustus 2020 di Desa Dajan Peken Wilayah Kerja Puskesmas Tabanan III Kecamatan Tabanan Kabupaten Tabanan diketahui jumlah total WUS IVA (30-50 tahun) sebanyak 1170 orang. Hasil wawancara pada enam WUS, diketahui dua orang mempunyai sikap yang baik sedangkan empat orang lagi mempunyai sikap yang kurang baik. Dimana empat orang tersebut enggan untuk melakukan IVA dan bahkan melakukan IVA hanya sekedar untuk melakukan pemeriksaan IVA bukan sebagai pemeriksaan rutin yang harus dilakukan pada usia produktif untuk mendeteksi dini kanker serviks dan tidak dilakukan berkesinambungan. Terkait dengan masalah serta uraian diatas WUS perlu mengetahui pemahaman atau informasi mengenai IVA dan WUS juga perlu mengetahui bagaimana cara bersikap positif dalam melakukan pemeriksaan IVA agar secara dini dapat mencegah terjadinya kanker serviks.

Penelitian ini bertujuan untuk mengetahui hubungan antara sikap Wanita Usia Subur (WUS) dengan upaya deteksi dini Inspeksi Visual dengan Asam Asetat (IVA) di Desa Dajan Peken Kabupaten Tabanan.

\section{Metode Penelitian}

Jenis penelitian ini merupakan penelitian kuantitatif dengan rancangan analitik korelatif dengan dengan cross sectional. Penelitian ini dilaksanakan pada tanggal 1-10 Februari 2021 di Desa Dajan Peken Wilayah Kerja Puskesmas Tabanan III. Populasi 
dalam penelitian ini adalah jumlah WUS usia 30-50 tahun sebanyak 87 orang. Penelitian ini menggunakan Non probability sampling dengan teknik purposive sampling dengan jumlah sampel yang diambil untuk diteliti adalah 71 orang. Teknik analisa data yang digunakan untuk menguji hipotesis adalah dengan uji non-parametrik yaitu uji Chi Square dengan tingkat kemaknaan signifikansi $(0,05)$.

\section{Hasil dan Pembahasan.}

Tabel 1 Distribusi Frekuensi Responden Berdasarkan Usia WUS di Desa Dajan Peken Kabupaten Tabanan

\begin{tabular}{cccc}
\hline No & Usia & Frekuensi (f) & Persentase (\%) \\
\hline 1 & $25-35$ tahun & 8 & 11,3 \\
\hline 2 & $36-45$ tahun & 47 & 66,2 \\
\hline 3 & $46-55$ tahun & 16 & 22,5 \\
\hline & Total & 71 & 100 \\
\hline
\end{tabular}

Tabel 2 Distribusi Frekuensi Responden Berdasarkan Pendidikan Terakhir WUS Di Desa Dajan Peken Kabupaten Tabanan

\begin{tabular}{clccc}
\hline No & & Pendidikan & Frekuensi (f) & Persentase (\%) \\
\hline 1 & SD & 4 & 5,6 \\
\hline 2 & SMP & 4 & 5,6 \\
\hline 3 & SMA & 37 & 52,1 \\
\hline 4 & Diploma & 12 & 16,9 \\
\hline 5 & Sarjana & 14 & 19,7 \\
\hline \multicolumn{2}{r}{} & Total & 71 & 100 \\
\hline
\end{tabular}

Tabel 3 Distribusi Frekuensi Responden Berdasarkan Pekerjaan WUS di Desa Dajan Peken Kabupaten Tabanan

\begin{tabular}{clcc}
\hline No & \multicolumn{1}{c}{ Pekerjaan } & Frekuensi (f) & Persentase (\%) \\
\hline 1 & Tidak Bekerja & 3 & 4,2 \\
\hline 2 & Swasta & 39 & 54,9 \\
\hline 3 & Wiraswasta & 20 & 28,2 \\
\hline 4 & PNS & 9 & 12,7 \\
\hline \multicolumn{2}{r}{ Total } & 71 & 100 \\
\hline
\end{tabular}

Tabel 4 Distribusi Frekuensi Responden Berdasarkan Sikap WUS di Desa Dajan Peken Kabupaten Tabanan

\begin{tabular}{|c|c|c|c|}
\hline No & Sikap & Frekuensi (f) & Persentase $(\%)$ \\
\hline 1 & Baik & 23 & 32,4 \\
\hline 2 & Cukup & 44 & 62,0 \\
\hline 3 & Kurang & 4 & 5,6 \\
\hline & Total & 71 & 100 \\
\hline
\end{tabular}

Tabel 5 Distribusi Frekuensi Responden Berdasarkan Upaya Deteksi Dini Kanker Serviks Dengan Tes IVA Di Desa Dajan Peken Kabupaten Tabanan

\begin{tabular}{clcc}
\hline No & Upaya Deteksi Dini IVA & Frekuensi (f) & Persentase (\%) \\
\hline 1 & Pernah IVA & 56 & 78,9 \\
\hline 2 & Belum Pernah IVA & 15 & 21,1 \\
\hline & Total & 71 & 100 \\
\hline
\end{tabular}


Tabel 6 Distribusi Tabulasi Silang antara Sikap WUS dengan Upaya Deteksi Dini Kanker Serviks Dengan IVA di Desa Dajan Peken Kabupaten Tabanan

\begin{tabular}{lccccc}
\hline \multirow{2}{*}{ Sikap WUS } & \multicolumn{2}{c}{ Upaya Tes IVA } & Total & P value & \multirow{2}{*}{$\boldsymbol{X}^{\mathbf{2}}$} \\
\cline { 2 - 4 } & Pernah & $\begin{array}{c}\text { Belum } \\
\text { Pernah }\end{array}$ & & & \\
\cline { 2 - 4 } $\begin{array}{l}\text { Baik } \\
(\%)\end{array}$ & 19 & 4 & 23 & & \\
\cline { 2 - 4 } $\begin{array}{l}\text { Cukup } \\
(\%)\end{array}$ & 82,6 & 17,2 & 100 & & \\
\cline { 2 - 4 } Kurang & 37 & 7 & 44 & & \\
$(\%)$ & 84,1 & 15,9 & 100 & & \\
\cline { 2 - 4 } Total & 0 & 4 & 4 & & \\
$(\%)$ & 0,0 & 100 & 100 & & \\
\hline
\end{tabular}

Berdasarkan Tabel 4 dapat diketahui dari 71 responden, sikap wanita usia subur sebagian besar cukup yaitu sebesar $62,0 \%$. Hasil penelitian sejalan dengan penelitian yang dilakukan oleh Shinta (2019) bahwa sebagian besar wanita usia subur yang memiliki sikap dalam kategori cukup yaitu 46 responden (76,67\%). Berdasarkan hasil jawaban responden pada lembar kuesioner pada sikap wanita usia subur terhadap beberapa indikator sikap pada pemeriksaan IVA bahwa sebagian besar dari jawaban wanita usia subur terhadap pernyataan tersebut adalah dalam kategori sikap cukup.

Sikap ini terdiri dari empat tingkatan, yaitu menerima, merespons, menghargai, dan bertanggung jawab. Faktor-faktor yang mempengaruhi sikap antara lain adalah pengalaman pribadi, pengaruh orang lain yang dianggap penting, pengaruh kebudayaan, media massa, lembaga pendidikan dan lembaga agama, dan faktor emosional (Azwar, 2012).

Berdasarkan Tabel 2 dapat diketahui dari 71 responden sebagian besar pendidikan terakhir wanita usia subur yaitu SMA yaitu sebanyak 52,1\%. Hal ini sesuai dengan teori Wawan A dan Dewi M (2011) bahwa pendidikan diperlukan untuk mendapatkan informasi misalnya hal-hal yang menunjang kesehatan seperti pelaksanaan IVA sehingga dapat meningkatkan sikap yang baik dalam upaya deteksi dini kanker serviks dengan IVA.

Berdasarkan Tabel 3 dapat diketahui dari 71 responden sebagian besar pekerjaan WUS adalah Swasta yaitu sebanyak 54,9\%.
Menurut Linda (2018) pekerjaan yang dilakukan seseorang akan mempengaruhi pola pikir terhadap suatu tindakan yang kan dilakukan. Seseorang yang memiliki pekerjaan di luar rumah tentunya akan banyak memiliki tingkat sosial yang lebih tinggi dibandingkan seseorang yang tidak bekerja atau berdiam diri di rumah.

Menurut peneliti sikap WUS yang cukup dalam penelitian ini ditunjukkan dalam jawaban kuesioner yang sebagian besar menyatakan belum mempunyai keinginan atau kesediaan dalam melakukan pemeriksaan IVA, dan sebagian masih menganggap bahwa pemeriksaan IVA tidak terlalu penting untuk dilakukan, apalagi untuk melakukan pemeriksaan IVA secara rutin minimal 1 tahun satu kali, serta yang kurang adanya dorongan darinorang yang dianggap penting yaitu suami atau teman.

Berdasarkan Tabel 5 dapat diketahui dari 71 responden upaya WUS dalam deteksi dini kanker serviks dengan IVA adalah sebagian besar yang sudah pernah IVA sebanyak 56 responden $(78,9 \%)$. Hasil penelitian ini sejalan dengan penelitian yang dilakukan oleh Indrayani Triana (2018) didapatkan hasil bahwa minat tinggi dalam deteksi dini menggunakan inspeksi visual asam asetat sebanyak 58 orang (63\%). Hal ini sejalan dengan teori yang dikemukan oleh Green et al dalam Anies (2016) menyatakan bahwa perilaku kesehatan seseorang atau masyarakat salah satunya ditentukan oleh sikap, yang dalam hal ini yaitu upaya deteksi dini kanker serviks dengan tes IVA 
Kanker serviks biasanya terjadi pada wanita yang telah berumur, tetapi bukti statistik menunjukkan bahwa kanker leher rahim juga dapat menyerang wanita yang berumur antara 20 sampai 30 tahun (Nita Norma, 2013). Berdasarkan Tabel 1 dapat diketahui dari 71 responden sebagian besar WUS berumur 36-45 tahun yaitu sebesar 66,2\%. Hal ini sesuai dengan teori Azwar (2012) bahwa semakin cukup umur, tingkat kematangan dan kekuatan seseorang akan lebih matang dalam berpikir dan bekerja. Umur juga dapat berpengaruh dalam pola pikir termasuk dalam upaya pengambilan keputusan seperti keinginan untuk upaya pencegahan kanker serviks dengan IVA.

Berdasarkan hasil uji analisis Chi-Square yaitu didapatkan hasil $p$ value $0,000<\alpha 0,05$ dan hasil hitung $\mathrm{x}^{2}$ diperoleh nilai $\mathrm{x}^{2}$ hitung $15,845>x^{2}$ tabel 5,991 maka dapat dikatakan ada hubungan antara sikap wanita usia subur dengan upaya deteksi dini kanker serviks dengan IVA di Desa Dajan Peken Kabupaten Tabanan. Hasil penelitian ini sejalan dengan Artianingsih (2011) yang menyatakan bahwa ada hubungan antara sikap wanita usia subur dengan perilaku pemeriksaan IVA di Puskesmas Blooto, Kecamatan Prajurit Kulon, Kota Mojokerto.

Terwujudnya sikap agar menjadi suatu perbuatan yang nyata (praktik) diperlukan faktor pendukung atau kondisi yang memungkinkan. Sikap sangat menentukan seseorang ke arah lebih baik. Upaya yang dapat dilakukan untuk membentuk sikap tersebut dapat diwujudkan melalui pemberdayaan tenaga kesehatan untuk memberikan pemahaman tentang pentingnya deteksi dini kanker serviks melalui metode IVA kepada masyarakat secara berkala. Sikap positif akan memunculkan perilaku WUS yang baik untuk melakukan deteksi dini kanker serviks melalui metode IVA (Widya, 2019).

Menurut peneliti kesadaran dan kemauan atau inisiatif dari diri sendiri untuk memeriksakan kesehatan khususnya untuk mengetahui deteksi dini kanker serviks akan meningkatkan sikap WUS dalam melakaukan upaya deteksi dini kanker serviks dengan
IVA. Interaksi dengan orang sekitar dan kemauan dari dalam diri sangat mempengaruhi terhadap pembetukan sikap seseorang. Peran serta keluarga, suami, dan teman, petugas kesehatan sangan dibutuhkan WUS dalam memperoleh informasi tentang dalam upaya deteksi kanker serviks dengan IVA.

\section{Simpulan}

Berdasarkan hasil penelitian yang dilakukan kepada 71 responden wanita usia subur tentang hubungan antara sikap wanita usia subur dengan upaya deteksi dini kanker serviks dengan IVA di Desa Dajan Peken Kabupaten Tabanan maka dapat disimpulkan bahwa ada hubungan antara sikap wanita usia subur dengan upaya deteksi dini kanker serviks dengan IVA di Desa Dajan Peken Kabupaten Tabanan dengan $p$ value $0,000<$ 0,05 .

\section{Referensi}

Arief, D. 2017. Pasien Kanker Serviks di RSUP H. Adam Malik Medan Tahun 2011 (Jurnal). Medan. Fakultas Kedokteran USU

Artiningsih, Ninik. 2017. Hubungan Antara Tingkat Pengettahuan Dan Sikap Wanita Usia Subur Dengan Pemeriksaan Inspeksi Visual Asam Asetat Dalam Rangka Deteksi Dini Kanker Cerviks. Surakarta Universitas Sebelas Maret.

Azizah. 2015. Hubungan Pengetahuan Tentang Kanker Serviks dengan Partisipasi Wanita dalam program deteksi dini kanker Serviks (Jurnal). Jakarta : Universitas Pembangunan Nasional Veteran

Azwar, S. 2012. Sikap Manusia. Yogyakarta: Liberty

Bertiani, S. 2017. Cara Cerdas Menghadapi Kanker Serviks (Leher Rahim). Yogyakarta: Genius Printika

BKKBN. 2010. Peningkatan Partisipasi Pria Dalam Keluarga Berencana dan Kesehatan Reproduksi. Jakarta

Dinkes Kabupaten Tabanan. 2014. Rekapan Kegiatan IVA Kabupaten Tabanan tahun 2010-1014 
Fitriana, N.A dan Ambarini, T.K. 2017. Kualitas Hidup Pada Penderita Kanker Serviks Yang Menjalani Pengobatan Radioterapi. Jurnal Psikologi Klinis dan Kesehatan Mental Vol 1 No.02 hal 123129

Hidayat. 2014. Metode Penelitian Kebidanan dan Teknik Analisis Data. Jakarta: Salemba Medika

Indrayani, Triana. 2018. "Jurnal Hubungan Pengetahuan dan Sikap Wanita Usia Subur Terhadap Minat Melakukan IVA Test di Puskesmas Kecamatan Jatinegara". Jakarta. Universitas Nasioal Jakarta. (Online) (http://ejurnal.husadakaryajaya. ac.id/, Di Akses pada Tanggal 09 Januari 2021)

Martini. 2016. Hubungan Karakteristik, Pengetahuan Dan Sikap Wanita Pasangan Usia Subur Dengan Tindakan Pemeriksaan Pap Smear Di Puskesmas Sukawati II. Denpasar: Universitas Udayana.

Mubarak, W. 2011. Promosi Kesehatan Sebuah Pengantar Proses Belajar Mengajar dalam Pendidikan. Yogyakarta: Graha Ilmu

Norma, N. 2013. Asuhan Kebidanan Patologi. Yogyakarta: Nuha Medika

Nuranna, L. 2010. Pedoman Tatalaksana Kanker. Jakarta: Fakultas Kedokteran Universitas Indonesia

Septiani, S. 2017. Promosi Kesehatan Pada Wanita Usia Subur (Jurnal). Banjarmasin. Akbid Sari Mulya Banjarmasin

Smart, A. 2015. Kanker Organ Reproduksi. Yogyakarta: A Plus Books.

Sumiati. 2013. Hubungan Pengetahuan dan Sikap Wanita Usia Subur (WUS) terhadap Pemeriksaan Pap smear di RS Bersalin Restu Makassar. 2,7-13. Makassar: STIKES Nani Hassanudin

Wawan dan Dewi. 2010.Teori dan Pengukuran Pengetahuan, Sikap dan Perilaku Manusia, Yogyakarta : Nuha Medika
Wong, et al. 2016. Knowledge and awareness of cervical cancer and screening among Malaysian women who have never had a Pap smear: a qualitative study (journal). Singapura Med 